Research Article

\title{
CYP3A5 genotyping for assessing the efficacy of treatment with simvastatin and atorvastatin
}

Genovefa Kolovou ${ }^{1}$, Vana Kolovou ${ }^{1,2}$, Georgia Ragia ${ }^{3}$, Constantinos Mihas ${ }^{4}$, Olga Diakoumakou ${ }^{1}$, Ioannis Vasiliadis ${ }^{1}$, Sophie Mavrogeni ${ }^{1}$, Vassiliki Vartela ${ }^{1}$ and Vangelis G Manolopoulos ${ }^{3}$

${ }^{1}$ Department of Cardiology, Onassis Cardiac Surgery Center, Athens, Greece.

${ }^{2}$ Molecular Immunology Laboratory, Onassis Cardiac Surgery Center, Athens, Greece.

${ }^{3}$ Laboratory of Pharmacology, Medical School, Democritus University of Thrace, Alexandroupolis, Greece.

${ }^{4}$ Department of Internal Medicine, Kimi General Hospital, Kimi, Greece.

\begin{abstract}
In this work, we examined the impact of polymorphism in the cytochrome P450 (CYP) $3 A 5$ gene, CYP3A5*1 $6986 \mathrm{~A}$ $>$ G, rs 776746), on the reduction in the lipid levels caused by simvastatin and atorvastatin. We studied 350 hyperlipidemic patients who received $10-40 \mathrm{mg}$ of atorvastatin $(n=175)$ or simvastatin $(n=175)$ daily. Genotyping for CYP3A5 was done by PCR-RFLP analysis. Differences in the lipid profile before and after treatment were expressed as the \% difference. The frequency of CYP3A5 polymorphism was $13.4 \%$ for heterozygotes and $86.6 \%$ for homozygotes. Comparison of the responses to same dose of each drug showed that the highest \% difference was associated with total cholesterol (TC) in subjects receiving atorvastatin $40 \mathrm{mg}$ compared with simvastatin $40 \mathrm{mg}$ $(p=0.048)$. However, comparison of the responses to equivalent doses of atorvastatin vs. simvastatin revealed no difference in the \% change in any of the lipid parameters examined. In individuals with the same CYP3A5 genotype, a head to head comparison of the efficacy of the same dose of simvastatin vs. atorvastatin revealed an advantage for atorvastatin. For equivalent doses of atorvastatin vs. simvastatin there was no difference in the \% change in any of the lipid parameters examined. Within the same genotype there was a significant difference in the $\%$ change related to the drug treatment.
\end{abstract}

Keywords: atorvastatin, cholesterol, CYP3A5 gene polymorphism, simvastatin.

Received: August 14, 2014; Accepted: November 16, 2014.

\section{Introduction}

Statins [3-hydroxy-3-methylglutaryl coenzyme A (HMG-CoA) reductase inhibitors] are the main drugs for the treatment of high plasma total cholesterol and lowdensity lipoprotein cholesterol (TC and LDL-C, respectively) concentrations. The recommended plasma concentrations of LDL-C in very high- and high-risk patients are extremely strict $(<70 \mathrm{mg} / \mathrm{dL}$ and $<100 \mathrm{mg} / \mathrm{dL}$, respectively), with a trend to $<70 \mathrm{mg} / \mathrm{dL}$ also for high-risk patients (Grundy et al., 2004) or, according to new guidelines, a decrease in LDL-C of $>50 \%$ (Stone et al., 2014). However, there is considerable variation in the response of TC and LDL-C (25-60\% reduction) to statins that remains poorly understood. The most common problems are inappropriate drug category or dose selection, side effects and inadequate dose titration. Genetic factors may contribute to this variability since non-genetic factors (age, sex, smok-

Send correspondence to Genovefa D. Kolovou. Onassis Cardiac Surgery Center, 356 Sygrou Ave 176 74, Athens, Greece. E-mail: genovefa@kolovou.com. ing, body category weight, race and others) have only a trivial effect on the response to statins.

Three genome-wide association studies (GWAS) of the response to statins and several candidate gene association studies have been reported (Thompson et al., 2005; Donnelly et al., 2008; Thompson et al., 2009; Barber et al., 2010; Deshmukh et al., 2012). From these studies, the consistent finding is that variants in the apolipoprotein $\mathrm{E}$ $(A P O E)$ gene region are associated with variation in the LDL-C response. In addition, clinical trials of atorvastatin, such as CARDS (Armani and Toth, 2006) and the Anglo-Scandinavian Outcomes Trial (ASCOT), found an association between the LDL-C response to atorvastatin that reached GWAS significance and the Lipoprotein (a) ( $L P A)$ and APOE genes (Deshmukh et al., 2012).

Simvastatin and atorvastatin are the most widely used statins, with an enormous amount of research on their lipid-lowering efficacy and other pleotropic actions (Kolovou et al., 2008). These statins are metabolized by two members of the cytochrome P450 superfamily, CYP3A4 and CYP3A5, which are encoded by the CYP $3 A 4$ and 
CYP3A5 genes, respectively (Prueksaritanont et al., 2003). The CYP3A5 gene is part of a cluster of cytochrome P450 genes on chromosome 7q21.1 and is determined by a single nucleotide polymorphism (SNP; 6986A $>\mathrm{G}$ ) that results in CYP3A5 (rs 776746) being either present and functional $(3 \mathrm{~A} 5 * 1)$ or entirely absent $(3 \mathrm{~A} 5 * 3)$. This cluster also includes a pseudogene, CYP3A5P1. Polymorphism in CYP $3 A 5$, particularly the presence of the $C Y P 3 A 5^{*} 3$ allele, is the major factor that modulates gene expression (Kuehl et al., 2001).

Despite the considerable amount of research that has been done on the functions of $P 450$ genes, few studies have assessed the practical relevance of various factors that regulate $P 450$ expression among individuals. As an extension of our previous research (Ragia et al., 2014a,b), in this study we investigated the impact of CYP $3 A 5$ gene polymorphism on the effectiveness of simvastatin $v s$. atorvastatin in patients with hypercholesterolemia.

\section{Materials and Methods}

\section{Subjects}

We genotyped 350 unrelated Greek subjects (227 men and 123 women) aged 18-75 years old with primary hypercholesterolemia. Additional inclusion criteria were a stable (regular) use of medication, with drugs that were unlikely to interfere with the lipid profile (patients with chronic heart disease were on cardioselective $\beta$-blockers and aspirin, patients with hypertension were on angiotensin-converting enzyme inhibitors), and a routine lifestyle for at least four weeks prior to screening for this study. Subjects with a history of renal or thyroid disease and uncontrolled diabetes mellitus were excluded. The subjects were randomly assigned to simvastatin or atorvastatin treatment for at least three months. Statin therapy can have an important effect on the lipid profile within one month of initiating treatment. However, in some patients, the dose of statin needs to be adjusted and an additional measurement of the lipid profile is required in the following months. This additional measurement three months after the first is enough to evaluate the maximum efficacy of statin treatment. The dose of simvastatin (10-40 mg/daily) or atorvastatin (10$40 \mathrm{mg} /$ daily) was adjusted if required, according to the National Cholesterol Education Program Adult Treatment Panel III (NCEP ATP III) treatment goal for LDL-C based on the risk category (LDL-C $<130 \mathrm{mg} / \mathrm{dL}$, high-risk $<100 \mathrm{mg} / \mathrm{dL}$ or very high-risk $<70 \mathrm{mg} / \mathrm{dL}$, which correspond to concentrations of $<3.4,<2.6$ and $<1.8 \mathrm{mmol} / \mathrm{L}$, respectively) (Stone et al., 2005). The \% decrease in LDL-C with statin treatment is usually predictable. However, in some cases, higher doses of a particular statin are required to achieve the recommended treatment goal. All subjects were taking simvastatin or atorvastatin as the only lipid-lowering drug. This study was approved by the Insti- tutional Review Board of the Onassis Cardiac Surgery Center.

\section{Determination of blood lipids}

Total cholesterol (TC), triglyceride (TG) and high density lipoprotein cholesterol (HDL-C) levels were measured with enzymatic colorimetric methods using a Roche Integra Biochemical analyser and commercially available kits (Roche Diagnostics Gmbh, Hannheim, Germany). The serum LDL-C levels were calculated using the Friedewald formula in subjects with TG levels $<400 \mathrm{mg} / \mathrm{dL}$ $(4.5 \mathrm{mmol} / \mathrm{L})$.

\section{Genotyping of the CYP $3 A 5^{\star} 3$ polymorphism}

Blood samples $(5 \mathrm{~mL})$ were collected by direct venipuncture from each patient into a vacutainer tube containing ethylenediaminetetraacetic acid (EDTA). DNA was extracted by using a QIAGEN-FlexiGene DNA kit. The polymerase chain reaction (PCR) was used to amplify the sequence of interest as previously described (Arvanitidis et al., 2007). The reaction mix consisted of $5 \mu \mathrm{L}$ of $10 \mathrm{x}$ buffer, $1.5 \mu \mathrm{L}$ of $1 \mathrm{mM} \mathrm{MgCl}_{2}, 0.4 \mu \mathrm{L}$ of $25 \mathrm{mM}$ dNTPs, $0.5 \mu \mathrm{L}$ of forward primer $(115 \mathrm{pmol} / \mu \mathrm{L}), 0.5 \mu \mathrm{L}$ of reverse primer (134 pmol/ $\mu \mathrm{L}), 0.5 \mu \mathrm{L}$ of Taq polymerase (5 U, HyTest) and $3 \mu \mathrm{L}$ of DNA in a final volume of $50 \mu \mathrm{L}$. The reaction involved an initial denaturation at $94{ }^{\circ} \mathrm{C}$ for $5 \mathrm{~min}$ followed by 40 cycles of denaturation at $94^{\circ} \mathrm{C}$ for $1 \mathrm{~min}$, annealing at $55^{\circ} \mathrm{C}$ for $1 \mathrm{~min}$ and extension at $72{ }^{\circ} \mathrm{C}$ for $1 \mathrm{~min}$, with a final extension at $72{ }^{\circ} \mathrm{C}$ for $10 \mathrm{~min}$. All amplifications were done in a PTC-200 thermocycler (MJ Research, Watertown, MA, USA).

The PCR product ( $293 \mathrm{bp}, 10 \mu \mathrm{L}$ aliquot) was digested in a $20 \mu \mathrm{L}$ reaction volume containing $5 \mathrm{U}$ of $S s p \mathrm{I}$ restriction enzyme (Takara Bio Inc.) at $37^{\circ} \mathrm{C}$ for $2.5 \mathrm{~h}$. The digested products were separated by electrophoresis on $2.5 \%(\mathrm{w} / \mathrm{v})$ agarose gels and visualized by staining with ethidium bromide in conjunction with a 25 bp molecular weight ladder (Invitrogen). The fragments obtained for the CYP $3 A 5^{*} 1$ allele were $148 \mathrm{bp}, 125 \mathrm{bp}$ and $20 \mathrm{bp}$ in size, while those for the $C Y P 3 A 5^{*} 3$ allele were $168 \mathrm{bp}$ and $125 \mathrm{bp}$. An internal positive control for the CYP $3 A 5 * 1$ allele (rare allele) was included in each PCR-restriction fragment length polymorphism (RFLP) run.

All samples were genotyped in duplicate. In addition, $10 \%$ of the samples were randomly selected and genotyped by a different investigator who was unaware of the outcome of previous analysis. The correct genotype was confirmed in all of these blind analyses. We therefore believe that our PCR-RFLP results are valid, with no need for further validation by Sanger sequencing or real-time PCR

\section{Statistical analysis}

All continuous variables were expressed as the median \pm interquartile range $\left(25^{\text {th }}-75^{\text {th }}\right.$ percentile, IQR $)$ since 
they deviated from a normal distribution. All categorical variables were shown as absolute and relative (percentage) frequencies. The differences in TC, TG, HDL-C and LDL-C before and after simvastatin treatment were also expressed as absolute or $\%$ differences; $\%$ differences were calculated using the relationship $=[$ (variable after - variable before)/variable before] x 100. Mann-Whitney U and Wilcoxon rank-sum statistics were used to assess the differences in continuous variables between different groups and before (baseline) and after treatment, respectively. All tests were two-sided with the level of significance set at $p<0.05$. The data were analyzed using the statistical software package $\operatorname{SPSS}^{\circledR}$ v.22 $\left(\mathrm{IBM}^{\circledR}\right)$.

\section{Results}

\section{Patient and treatment characteristics}

Table 1 shows the baseline characteristics of the patients. The majority of patients reached the required treatment levels within three months and in only $20 \%$ of the patients was the third or fourth measurement done at
4-6 months. The TC, LDL-C and TG concentrations decreased significantly with simvastatin and atorvastatin treatment, whereas HDL-C was unaltered. With regard to the statin dose, $11 \%$ of the patients were on $10 \mathrm{mg}, 26 \%$ were on $20 \mathrm{mg}$ and $13 \%$ on $40 \mathrm{mg}$ of simvastatin per day compared to $18 \%, 21 \%$ and $11 \%$ for these same doses, respectively, for atorvastatin.

\section{Genotype frequencies}

The genotype frequency of the CYP3A5 polymorphism was $86.6 \%$ for homozygous ( $H M$, non-expressors) and $13.4 \%$ for heterozygous (HT, expressors) individuals. The wild-type (WT) genotype was excluded from the analysis because of the small number of subjects with this genotype $(\mathrm{n}=2)$ and the lack of crucial data [Hardy-Weinberg equilibrium, $\mathrm{p}=0.178]$. The frequency of $C Y P 3 A 5$ expressors was in accordance with that previously reported for the Greek population (Arvanitidis et al., 2007; Kolovou et al., 2014; Ragia et al., 2014c). Gender was not associated with the CYP3A5 frequency $(\mathrm{p}=0.408)$.

\section{CYP3A5 genotypes and statin response}

Table 1 - Lipid profiles before and after treatment with simvastatin or atorvastatin.

\begin{tabular}{|c|c|c|c|c|c|c|c|}
\hline Drug & Lipid variable (mg/dL) & Median & IQR & & Median & IQR & p-value \\
\hline \multicolumn{8}{|c|}{ Simvastatin $(n=175)$} \\
\hline & TC before & 275 & 57 & TC after & 186 & 39 & $<0.001$ \\
\hline & TGL before & 150 & 96 & TGL after & 116 & 61 & $<0.001$ \\
\hline & HDL before & 47 & 17 & HDL after & 47 & 17 & 0.313 \\
\hline & LDL before & 188 & 52 & LDL after & 110 & 35 & $<0.001$ \\
\hline & $\mathrm{TC}$ (difference in mg/dL) & -91 & 56 & & & & \\
\hline & TGL (difference in mg/dL) & -29 & 66 & & & & \\
\hline & HDL (difference in mg/dL) & 1 & 11 & & & & \\
\hline & LDL (difference in mg/dL) & -82 & 53 & & & & \\
\hline & TC (difference in \%) & -33 & 15 & & & & \\
\hline & TGL (difference in \%) & -20 & 32 & & & & \\
\hline & HDL (difference in \%) & 2 & 23 & & & & \\
\hline & LDL (difference in \%) & -43 & 19 & & & & \\
\hline \multicolumn{8}{|c|}{ Atorvastatin $(\mathrm{n}=175)$} \\
\hline & TC before & 285 & 67 & TC after & 184 & 42 & $<0.001$ \\
\hline & TGL before & 152 & 115 & TGL after & 105 & 65 & $<0.001$ \\
\hline & HDL before & 46 & 20 & HDL after & 45 & 19 & 0.455 \\
\hline & LDL before & 198 & 61 & LDL after & 111 & 40 & $<0.001$ \\
\hline & $\mathrm{TC}$ (difference in mg/dL) & -99 & 61 & & & & \\
\hline & TGL (difference in mg/dL) & -42 & 79 & & & & \\
\hline & HDL (difference in $\mathrm{mg} / \mathrm{dL}$ ) & 0 & 12 & & & & \\
\hline & LDL (difference in mg/dL) & -87 & 59 & & & & \\
\hline & $\mathrm{TC}$ (difference in \%) & -34 & 17 & & & & \\
\hline & TGL (difference in \%) & -28 & 39 & & & & \\
\hline & HDL (difference in \%) & 0 & 25 & & & & \\
\hline & LDL (difference in \%) & -42 & 20 & & & & \\
\hline
\end{tabular}

HDL - high density lipoprotein cholesterol, IQR - interquartile range, LDL - low density lipoprotein cholesterol, TC - total cholesterol and TG - triglycerides. 
The TC, TG, HDL-C, LDL-C concentrations and \% differences before and after treatment based on genotype and regardless of the statin used are shown in Tables 1 and 2 and Figures 1 and 2. The decrease in TC, TG and LDL-C levels was significant for both genotypes, whereas HDL-C levels did not differ significantly. TC and LDL-C decreased significantly with both statins. In subjects with the $H M$ genotype, both statins decreased TG, whereas in subjects with the $H T$ genotype only simvastatin $20 \mathrm{mg}$ and atorvastatin $20 \mathrm{mg}$ decreased TG significantly $(\mathrm{p}=0.005$ and $\mathrm{p}=0.010$, respectively). Analysis of the responses to equivalent doses of atorvastatin and simvastatin $(20 \mathrm{mg} v s .40 \mathrm{mg}$ and $10 \mathrm{mg}$ vs. $20 \mathrm{mg}$, respectively) revealed no difference in the \% change in any of the lipid parameters examined.

\section{Dose-response according to CYP3A5 genotype}

\section{HT genotype}

The highest $\%$ differences for TC occurred in subjects receiving atorvastatin $40 \mathrm{mg}$ compared to the other treatment groups (simvastatin 10, 20 and $40 \mathrm{mg}: \mathrm{p}=0.011$, 0.007 and 0.048 , respectively, and atorvastatin 10 and

$20 \mathrm{mg}: \mathrm{p}=0.006$ and 0.028 , respectively). Similarly, the highest \% differences for LDL occurred in subjects receiving atorvastatin $40 \mathrm{mg}$ compared to the other treatment groups (simvastatin 10 and $20 \mathrm{mg}$ : $\mathrm{p}=0.026$ and 0.004 , respectively, and atorvastatin 10 and $20 \mathrm{mg}: \mathrm{p}=0.032$ and $\mathrm{p}=0.017$, respectively), except for simvastatin $40 \mathrm{mg}$ $(\mathrm{p}=0.802)$.

\section{HM genotype}

The highest $\%$ differences for TC occurred in subjects receiving atorvastatin $40 \mathrm{mg}$ compared to simvastatin $10 \mathrm{mg}(\mathrm{p}=0.010)$. The median HDL-C difference was significantly different between subjects treated with $20 \mathrm{mg}$ of simvastatin and those treated with $20 \mathrm{mg}$ of atorvastatin (2 vs. -3 , respectively, $\mathrm{p}=0.021$ ). The decrease in LDL was significantly higher in subjects receiving simvastatin $40 \mathrm{mg}$ or atorvastatin $40 \mathrm{mg}$ compared to those receiving simvastatin $10 \mathrm{mg}(\mathrm{p}=0.046$ and 0.002 , respectively).

\section{Discussion}
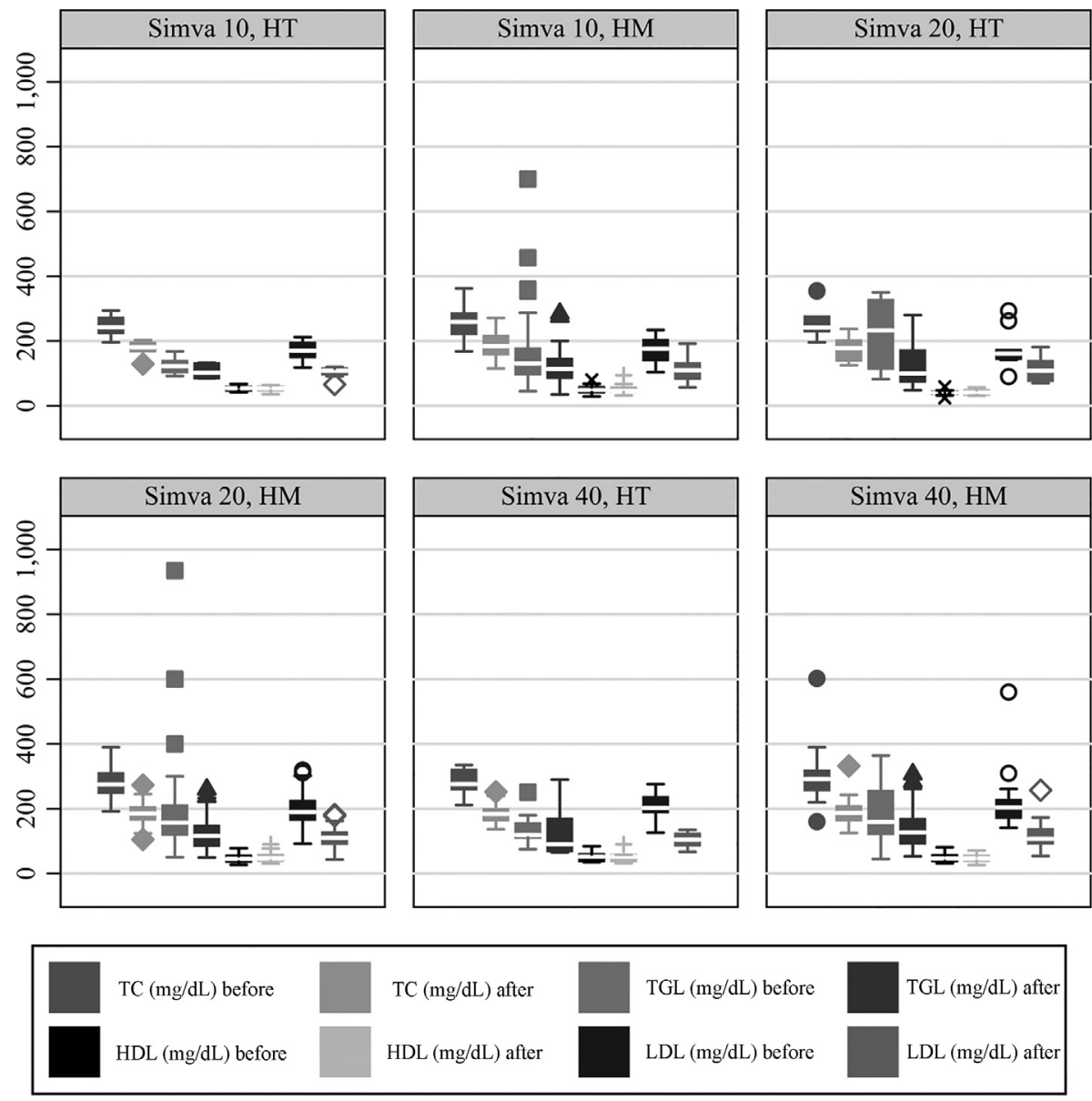

Figure 1 - Lipid values according to genotype and before and after treatment with simvastatin. HDL - high density lipoprotein cholesterol, HM CYP3A5 homozygous, HT - CYP3A5 heterozygous, LDL - low density lipoprotein cholesterol, Simva - simvastatin (10, 20 and $40 \mathrm{mg})$, TC - total cholesterol and TGL - triglycerides., Y axis describes the values (mg/dl) of TC, TGL, HDL and LDL before and after treatments. The Y axis is labeled from 0 to 1,000 . 

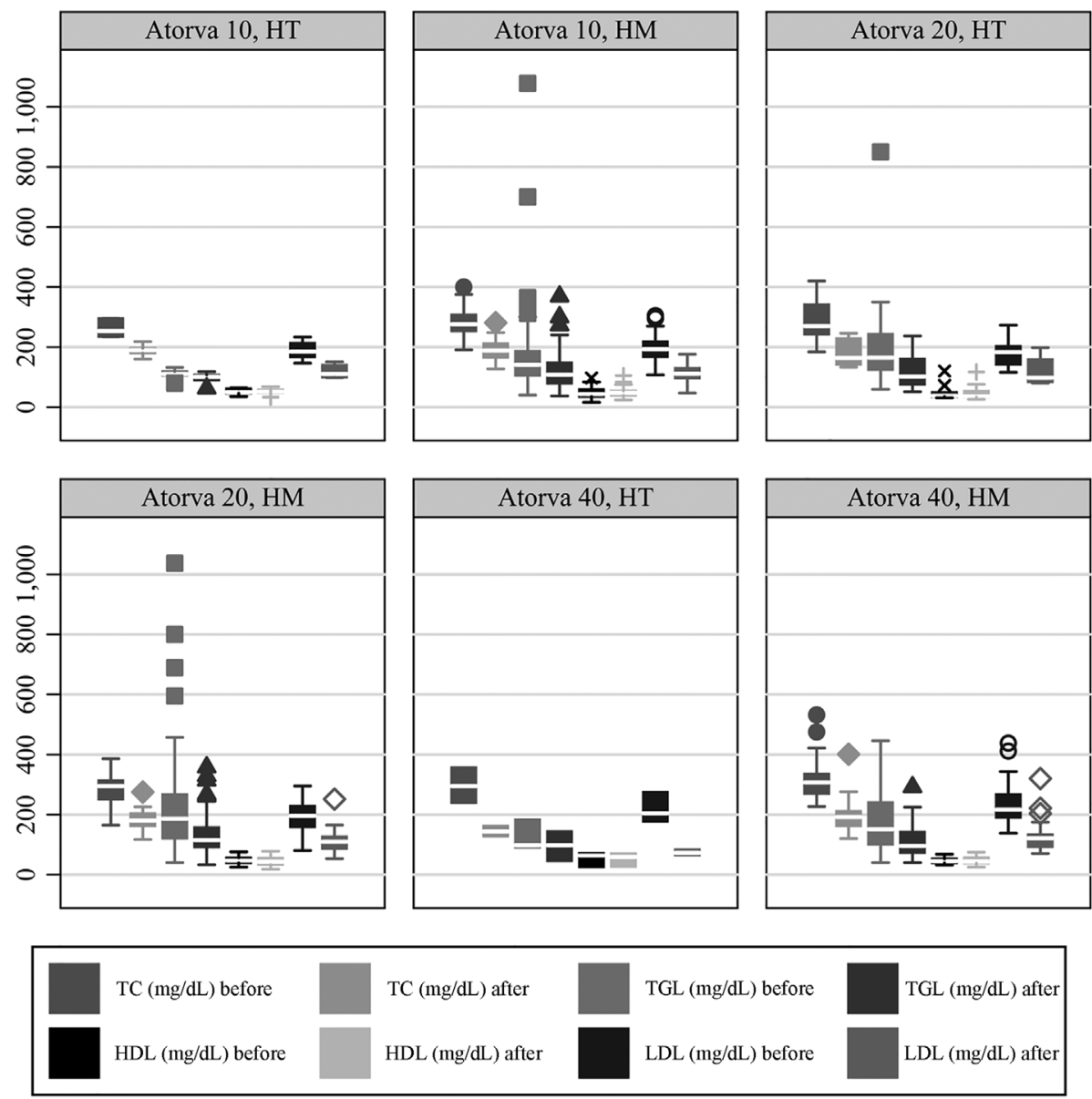

Figure 2 - Lipid values according to genotype and before and after treatment with atorvastatin. HDL - high density lipoprotein cholesterol, HM CYP3A5 homozygous, HT - CYP3A5 heterozygous, LDL - low density lipoprotein cholesterol, Simva - simvastatin (10, 20 and $40 \mathrm{mg})$, TC - total cholesterol and TGL - triglycerides. , Y axis describes the values (mg/dL) of TC, TGL, HDL and LDL before and after treatments. The Y axis is labeled from 0 to 1,000 .

In this study, we compared the efficacy of simvastatin vs. atorvastatin in relation to CYP $3 A 5$ polymorphism in Greek patients with hypercholesterolemia. The CYP3A5 gene may be one of the important genetic contributors to inter-individual and inter-racial differences in the response to and clearance of CYP3A-metabolized statins. Willrich et al. (2008) found that the $C Y P 3 A 5 * 3 A$ allele was associated with an attenuated cholesterol-lowering response to $10 \mathrm{mg}$ of atorvastatin in 139 non-African individuals. Kim et al. (2007) examined the simvastatin plasma concentration in 22 individuals over $12 \mathrm{~h}$ after the ingestion of a single dose of $20 \mathrm{mg}$ and found that the mean area $( \pm \mathrm{SD})$ under the plasma concentration-time curve for simvastatin in CYP $3 A 5^{*} 1 / * 1$ carriers was significantly lower than in CYP $3 A 5 * 3 / * 3$ carriers and that the mean oral clearance $( \pm$ SD) was also significantly different between CYP $3 A 5^{*} 1 / * 1$ and $C Y P 3 A 5 * 3 / * 3$ carriers. However, other pharmacokinetic parameters, including the peak plasma concentrations and half-life, did not differ between the genotypes. Kivistö et al. (2004) studied 69 Caucasian patients and found that lovastatin, simvastatin and atorvastatin were significantly less effective in CYP $3 A 5$ expressors than in non-expressors [mean \% reduction in serum TC was lower in CYP3A5 expressors than in non-expressors, i.e., $17 \% v s$. 31\%]. Kajinami et al. (2004) examined whether genetic variation in the CYP system [a promoter (A290G) and two non-synonymous polymorphisms (F189S and M445T) in the CYP3A4 gene locus] affected the statin response in 340 hypercholesterolemic patients who were treated with atorvastatin. The A290G variant allele was significantly associated with higher levels of post-treatment LDL cholesterol, whereas the M445T variant was associated with lower levels of LDL-C before and after treatment. Wang et al. (2011) studied the CYP3A4 polymorphism (rs35599367, C > T) in 235 patients receiving atorvastatin, simvastatin or lovastatin and found that $\mathrm{T}$ carriers required significantly lower statin doses than non- $\mathrm{T}$ carriers.

In the Genetic Effects On STATins (GEOSTAT-1) Study, which was a genetic substudy of Secondary Prevention of Acute Coronary Events-Reduction of Cholesterol to Key European Targets (SPACE ROCKET), a randomized, controlled trial comparing simvastatin to rosuvastatin that 


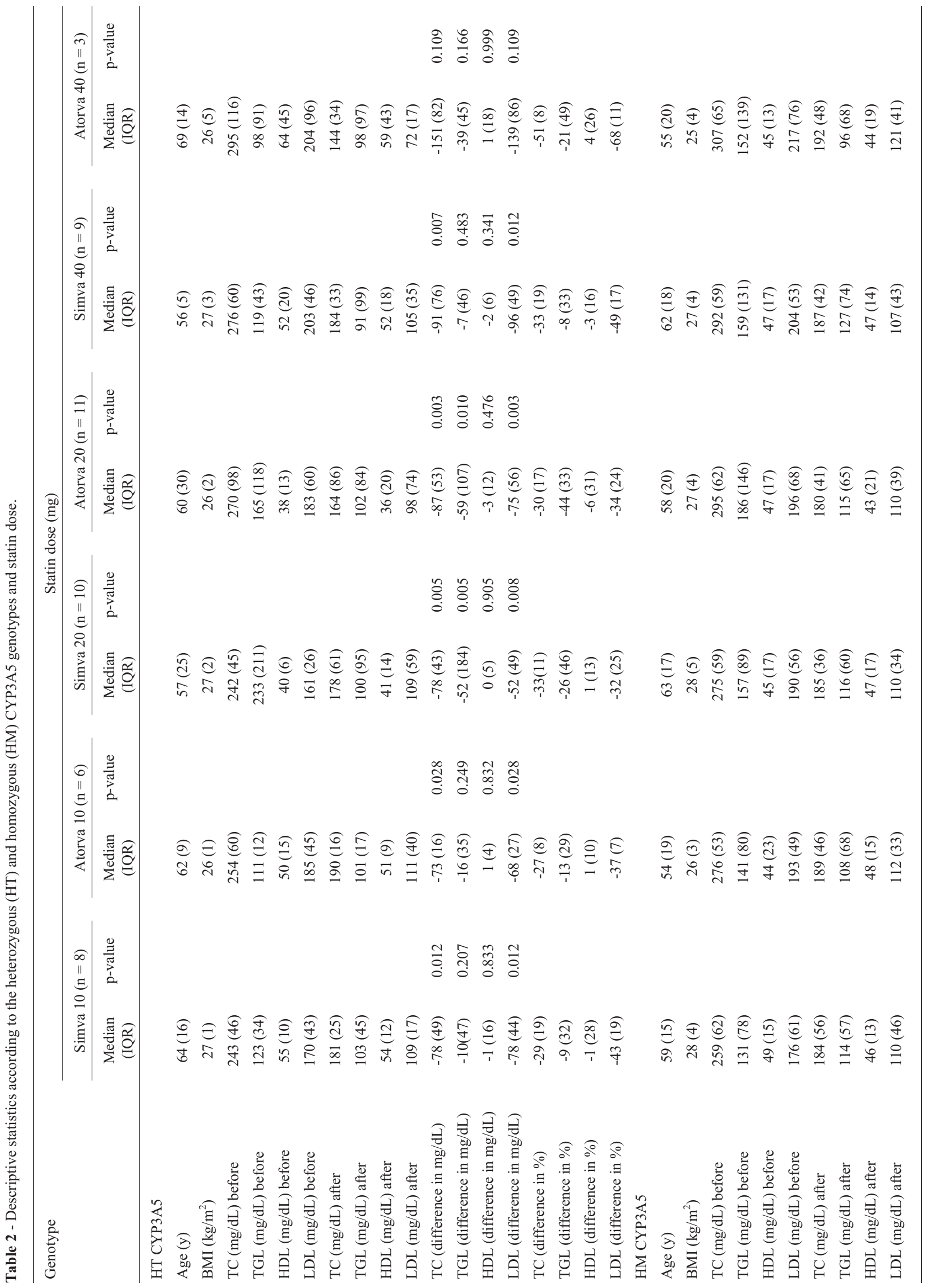




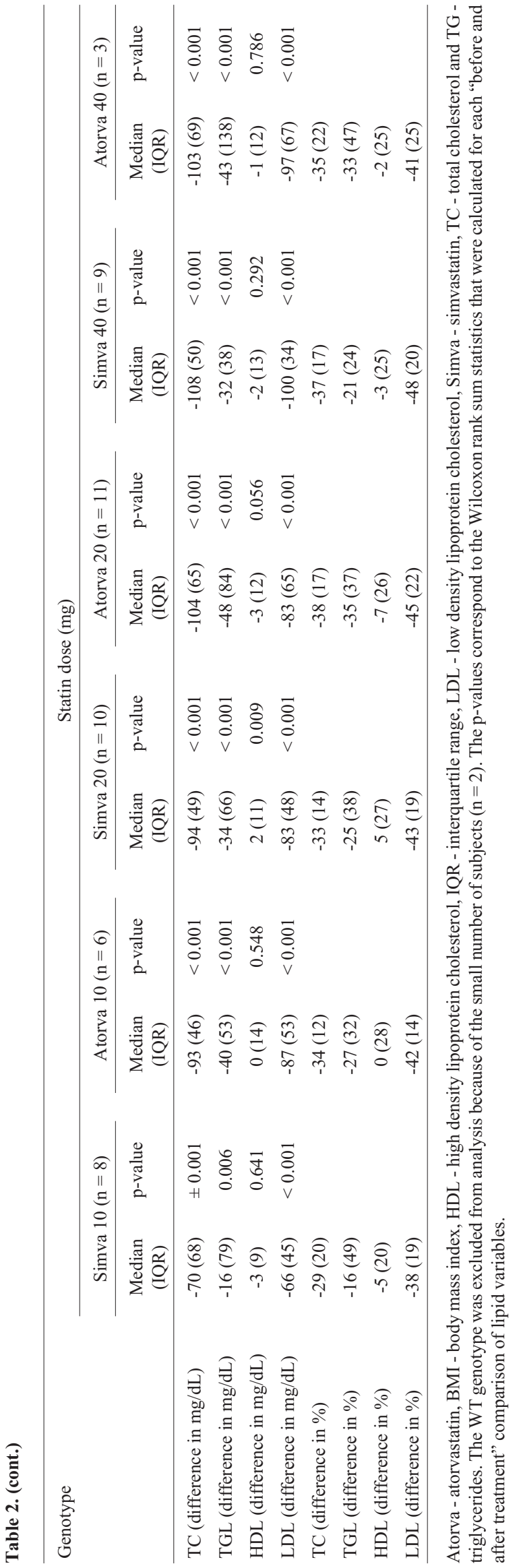

recruited 601 patients after myocardial infarction, the patients were genotyped for genes encoding the CYP450 $[C Y P 2 C 9 * 2(430 C>T), C Y P 2 C 9 * 3(1075 A>C)$, CYP2C19*2 $\left.(681 G>A), C Y P 3 A 5^{*} 1(6986 A>G)\right]$ and other genes. The LDL-C levels and the proportion of patients reaching the LDL-C target of $<70 \mathrm{mg} / \mathrm{dL}$ $(<1.81 \mathrm{mmol} / \mathrm{L})$ were assessed after three months. An enhanced response to rosuvastatin was seen in patients with CYP3A5 genotypes (Bailey et al., 2010). In contrast, Rosales et al. (2012) found no differences in the lipid profiles in relation to CYP $3 A 5$ polymorphism in Chilean subjects treated with atorvastatin. Gao et al. (2008) studied 217 patients who prospectively received atorvastatin and 199 patients who received simvastatin for four weeks and found that carrying $C Y P 3 A 4 * 1 G$ increased the lipid-lowering efficacy of atorvastatin and probably had no significant effect on the response to simvastatin treatment.

In a previous study, we examined the relationship between POR*28 (polymorphic enzyme P450 oxidoreductase, POR) polymorphism, which is associated with increased activity of CYP3A enzymes, and the response to atorvastatin and simvastatin (Ragia et al., 2014b). The POR $* 28$ allele was not associated with the lipid-lowering effect of atorvastatin and the results were replicated in an independent simvastatin-treated population. We also analyzed inter-individual variability in relation to CYP3A4 intron $6 \mathrm{C}>\mathrm{T}$ polymorphism (CYP3A4*22 allele, rs35599367) and the response to atorvastatin and simvastatin (Ragia et al., 2014a); there was no association with the lipid-lowering response to both drugs.

In the present study, comparison of equivalent doses of atorvastatin $v$ s. simvastatin revealed no significant difference in the $\%$ change in any of the lipid parameters examined. However, comparison of the same drug dose showed higher \% differences for TC in individuals receiving atorvastatin compared with simvastatin. A limitation of this study is the rather small number of subjects used. However, few studies have examined the relationship between the statin (simvastatin or atorvastatin)-mediated decrease in LDL-C and the subjects genotype, or between the CYP3A5 polymorphism and the efficacy of these two statins.

The gap between pharmacogenomics and personalized therapy in clinical practice is still very wide, with no guarantee that it will ever be bridged. For this reason, studies of the type described here are very important. Individualized therapy could be practical when the efficacy and side effects of a drug are simple and well-defined and a major goal could be reached when a phenotype-genotype association with a drug response is evaluated. In practical terms, personalized therapy is designed to identify patients who are hyper- or hypo-responders to drugs, as well as individuals who are prone to drug toxicity. However, genomic treatment has not moved as fast as expected, primarily because of scientific and economic difficulties. For treatment with statins, it is much cheaper to change the type of statin, to in- 
crease the dose or to use combination therapy together with statin treatment rather than perform expensive genotyping, although the cost of DNA sequencing is decreasing radically. Even for well-defined genetic variants such as $A P O E$ or cholesteryl ester transport protein (CETP) gene polymorphisms that have reproducible and significant consequences for drug therapy, general recognition of this relationship by the medical community can be slow.

In conclusion, in a head to head comparison of the efficacy of the same dose of simvastatin $v s$. atorvastatin in individuals with the same CYP3A5 genotype, we found an advantage for atorvastatin, although equivalent doses of atorvastatin $v s$. simvastatin showed no difference in the \% change in any of the lipid parameters examined. Of particular interest was the finding that within the same genotype there was an important difference in the $\%$ change according to drug treatment.

\section{References}

Armani A and Toth PP (2006) The CARDS trial: diabetic patients dealt a winning hand. Curr Atheroscler Rep 8:429-432.

Arvanitidis K, Ragia G, Iordanidou M, Kyriaki S, Xanthi A, Tavridou A and Manolopoulos VG (2007) Genetic polymorphisms of drug-metabolizing enzymes CYP2D6, CYP2C9, CYP2C19 and CYP3A5 in the Greek population. Fundam Clin Pharmacol 21:419-426.

Bailey KM, Romaine SP, Jackson BM, Farrin AJ, Efthymiou M, Barth JH, Copeland J, McCormack T, Whitehead A, Flather MD, et al. (2010) Hepatic metabolism and transporter gene variants enhance response to rosuvastatin in patients with acute myocardial infarction: the GEOSTAT-1 Study. Circ Cardiovasc Genet 3:276-285.

Barber MJ, Mangravite LM, Hyde CL, Chasman DI, Smith JD, McCarty CA, Li X, Wilke RA, Rieder MJ, Williams PT, et al. (2010) Genome-wide association of lipid-lowering response to statins in combined study populations. PLoS One 5:e9763.

Deshmukh HA, Colhoun HM, Johnson T, McKeigue PM, Betteridge DJ, Durrington $\mathrm{PN}$, Fuller $\mathrm{JH}$, Livingstone $\mathrm{S}$, Charlton-Menys V, Neil A, et al. (2012) Genome-wide association study of genetic determinants of LDL-c response to atorvastatin therapy: importance of $\mathrm{Lp}(\mathrm{a})$. J Lipid Res. 53:1000-1011.

Donnelly LA, Palmer CN, Whitley AL, Lang CC, Doney AS, Morris AD and Donnan PT (2008) Apolipoprotein E genotypes are associated with lipid-lowering responses to statin treatment in diabetes: a Go-DARTS study. Pharmacogenet Genomics 18:279-287.

Gao Y, Zhang LR and Fu Q (2008) CYP3A4*1G polymorphism is associated with lipid-lowering efficacy of atorvastatin but not of simvastatin. Eur J Clin Pharmacol 64:877-882.

Grundy SM, Brewer HB Jr, Cleeman JI, Smith SC Jr, Lenfant C, National Heart, Lung, and Blood Institute, and American Heart Association (2004) Definition of metabolic syndrome: report of the National Heart, Lung, and Blood Institute/American Heart Association conference on scientific issues related to definition. Arterioscler Thromb Vasc Biol 24:e13-18.
Kajinami K1, Brousseau ME, Ordovas JM and Schaefer EJ (2004) CYP3A4 genotypes and plasma lipoprotein levels before and after treatment with atorvastatin in primary hypercholesterolemia. Am J Cardiol 93:104-107.

Kim KA, Park PW, Lee OJ, Kang DK and Park JY (2007) Effect of polymorphic CYP3A5 genotype on the single-dose simvastatin pharmacokinetics in healthy subjects. J Clin Pharmacol 47:87-93.

Kivistö KT, Niemi M, Schaeffeler E, Pitkälä K, Tilvis R, Fromm MF, Schwab M, Eichelbaum M and Strandberg T (2004) Lipid-lowering response to statins is affected by CYP3A5 polymorphism. Pharmacogenetics 14:523-525.

Kolovou GD, Katerina A, Ioannis V and Cokkinos DV (2008) Simvastatin: two decades in a circle. Cardiovasc Ther 26:166-178

Kolovou G, Ragia G, Kolovou V, Mihas C, Katsiki N, Vasiliadis I, Mavrogeni S, Vartela V, Tavridou A and Manolopoulos VG (2014) Impact of CYP3A5 gene polymorphism on efficacy of simvastatin. Open Cardiovasc Med J 8:12-17.

Kuehl P, Zhang J, Lin Y, Lamba J, Assem M, Schuetz J, Watkins PB, Daly A, Wrighton SA, Hall SD, et al. (2001) Sequence diversity in CYP3A promoters and characterization of the genetic basis of polymorphic CYP3A5 expression. Nat Genet 27:383-391.

Stone NJ, Bilek S, Rosenbaum S (2005). Recent National Cholesterol Education Program Adult Treatment Panel III update: adjustments and options. Am J Cardiol 96(4A):53E-59E.

Prueksaritanont T, Ma B and Yu N (2003) The human hepatic metabolism of simvastatin hydroxy acid is mediated primarily by CYP3A, and not CYP2D6. Br J Clin Pharmacol $56: 120-124$.

Ragia G, Kolovou V, Tavridou A, Elens L, Tselepis AD, Elisaf M, Van Schaik RH, Kolovou G and Manolopoulos VG (2014a) No effect of CYP3A4 intron $6 \mathrm{C}>\mathrm{T}$ polymorphism (CYP3A4*22) on lipid-lowering response to statins in Greek patients with primary hypercholesterolemia. Drug Metabol Drug Interact doi: 10.1515/dmdi-2014-0021.

Ragia G, Kolovou V, Tavridou A, Elens L, Tselepis AD, Elisaf M, Van Schaik RH, Kolovou G and Manolopoulos VG (2014b) Lack of association of the p450 oxidoreductase $* 28$ single nucleotide polymorphism with the lipid-lowering effect of statins in hypercholesterolemic patients. Mol Diagn Ther $18: 323-331$

Ragia G, Giannakopoulou E, Karaglani M, Karantza IM, Tavridou A, Manolopoulos VG (2014c) Frequency of CYP450 enzyme gene polymorphisms in the Greek population: Review of the literature, original findings and clinical significance. Drug Metabol Drug Interact 29:235-248.

Rosales A, Alvear M, Cuevas A, Saavedra N, Zambrano T and Salazar LA (2012) Identification of pharmacogenetic predictors of lipid-lowering response to atorvastatin in Chilean subjects with hypercholesterolemia. Clin Chim Acta 413:495-501.

Stone NJ, Bilek S, Rosenbaum S (2005) Recent National Cholesterol Education Program Adult Treatment Panel III update: adjustments and options. Am J Cardiol 96:53E-59E.

Stone NJ, Robinson JG, Lichtenstein AH, Bairey Merz CN, Blum $\mathrm{CB}$, Eckel RH, Goldberg AC, Gordon D, Levy D, LloydJones DM, et al. (2014) 2013 ACC/AHA guideline on the treatment of blood cholesterol to reduce atherosclerotic cardiovascular risk in adults: a report of the American College 
of Cardiology/American Heart Association Task Force on Practice Guidelines. J Am Coll Cardiol 63:2889-2934.

Thompson JF, Hyde CL, Wood LS, Paciga SA, Hinds DA, Cox DR, Hovingh GK and Kastelein JJ (2009) Comprehensive whole-genome and candidate gene analysis for response to statin therapy in the Treating to New Targets (TNT) cohort. Circ Cardiovasc Genet 2:173-181.

Thompson JF, Man M, Johnson KJ, Wood LS, Lira ME, Lloyd DB, Banerjee P, Milos PM, Myrand SP, Paulauskis J, et al. (2005) An association study of 43 SNPs in 16 candidate genes with atorvastatin response. Pharmacogenomics J 5:352-358.
Wang D, Guo Y, Wrighton SA, Cooke GE and Sadee W (2011) Intronic polymorphism in CYP3A4 affects hepatic expression and response to statin drugs. Pharmacogenomics J 11:274-286.

Willrich MA, Hirata MH, Genvigir FD, Arazi SS, Rebecchi IM, Rodrigues AC, Bernik MM, Dorea EL, Bertolami MC, Faludi AA, et al. (2008) CYP3A53A allele is associated with reduced lowering-lipid response to atorvastatin in individuals with hypercholesterolemia. Clin Chim Acta 398:15-20.

Associate Editor: Jeremy Squire

License information: This is an open-access article distributed under the terms of the Creative Commons Attribution License, which permits unrestricted use, distribution, and reproduction in any medium, provided the original work is properly cited. 